\title{
Política de Saúde do Trabalhador no Brasil: Muitas Questões Sem Respostas
}

\section{National Worker's Health Policy: Many Questions Without Answers}

\author{
Maria Helena B. de Oliveira ${ }^{1}$ \\ Luiz Carlos F. Vasconcellos ${ }^{2}$
}

OLIVEIRA, M. H. B. de \& VASCONCELLOS, L. C. F. National Worker's Health Policy: Many Questions Without Answers. Cad. Saude Públ., Rio de Janeiro, 8 (2): 150-156, abr/jun, 1992.

The National Worker's Health Policy is analysed, pointing to such problems as undernotification of occupational diseases and work-related accidents, accountability fragmentation among various organizations, the importance worker's health policy in the context of the National Health Policy, and the lack of trained personnel.

This extremely serious situation should be reverted by structural changes in the productive processes, with the active participation of workers both in the stablishment and conduction of this policy.

Finally, this paper points to several issues that can contribute to future investigations, research and studies in this area.

Keywords: Health Policies; Workers; Health

\section{A SAÚDE DO TRABALHADOR NA RELAÇÃO ESTADO-SOCIEDADE}

A Política Nacional de Saúde do Trabalhador, enquanto parte da política para o setor saúde, está submetida a um movimento real e concreto de forças sociais, cuja expressão se intensifica na dinâmica das variáveis conjunturais presentes na relação Estado e Sociedade Civil.

A análise do discurso e das práticas de uma determinada política implica uma compreensão abrangente dos contextos sociais onde esta se realiza, considerando-se os niveis político, ideológico e econômico, que não podem ser tratados de forma estanque e separada.

Sob esta ótica, é necessário identificar estratégias capazes de construir uma nova ordem hegemônica na sociedade brasileira que abra

\footnotetext{
' Centro de Estudos da Saúde do Trabalhador e Ecologia Humana da Escola Nacional de Saúde Pública. Rua Leopoldo Bulhöes, 1480, Rio de Janeiro, RJ, 21041-210, Brasil.

2 Programa de Saúde do Trabalhador da Secretaria Estadual de Saude do Estado do Rio de Janeiro. Rua Méxica, 128, 3e andar, Rio de Janeira, RI, 20031-142, Brasil.
}

espaços para o equacionamento efetivo da questão social. Esta deverá ser capaz de incorporar as mudanças ocorridas na sociedade no periodo pós-ditatorial, como resultado do processo de democratização, que culminou na Carta Constitucional recém-promulgada. Deverá também corresponder, como bem assinala Faleiros (1984), à necessidade de resposta às transformaçōes sociais resultantes do processo de internacionalização da Economia. É nesta perspectiva que devem ser analisadas as politicas públicas no Brasil contemporâneo.

A dinâmica que se imprime na relação Estado-Sociedade Civil, que no caso da Saúde do Trabalhador envolve a relação capital-trabalho, não incorporou ainda a transformação necessária, capaz de responder às rápidas mudanças que vêm se impondo à sociedade brasileira neste contexto de democratização e internacionalização da Economia.

$O$ aprofundamento da análise implica desnudar a fundo o quadro existente, com todos os possíveis parâmetros capazes de serem demarcados, a despeito das dificuldades conhecidas em estabelecê-los. A incorporação de novas formas de abordagem da questão da Saúde do 
Trabalhador, atrelada ao debate que ora segue em curso sobre a despoluição da produção e o desenvolvimento de tecnologias limpas, deverá contribuir para enriquecer a discussão nos próximos anos. A expectativa é de que a ampliação do enfoque contribua para que as medidas capazes de enfrentar e reverter os perfis epidemiológicos de morbi-mortalidade dos trabalhadores sejam compativeis com as rápidas transformações sociais e com as mudanças na correlação de forças na dinâmica da relação entre o Estado e a Sociedade Civil.

\section{TRABALHO: MORTE E DOENÇA}

Diversos estudos utilizando os dados oficiais demonstram um quadro extremamente grave de morbi-mortalidade dos trabalhadores brasileiros, que vem se acentuando ao longo dos anos. A despeito de uma diminuição do número absoluto de acidentes de trabalho registrados nos últimos anos, vem ocorrendo um aumento progressivo do indice de letalidade, o que de per si aponta para a gravidade do problema.

Estudos como os de Tambellini (1974), Possas (1981), Mendes (1986) e outros autores apontam para a gravidade dos problemas de saúde dos trabalhadores brasileiros, em decorrência dos processos de trabalho a que estes estão submetidos.

Dentre os efeitos na saúde causados pelo trabalho, como define Mendes (1986), encontramos os "agudos", que são os acidentes de trabalho $e$ as intoxicações. A partir de dados oficiais de trabalhadores cobertos pelo sistema urbano da Previdência Social, o mesmo autor refere que os acidentes do trabalho, cuja incidência vem aparentemente caindo a partir de 1973, ainda atingem mais de um milhão de trabalhadores por ano. Se levarmos em conta o provável sub-registro e os significativos contingentes da PEA não incluidos nesta estatística (por exemplo, as trabalhadores rurais, os do setor informal e/ou os que não contribuem para a Previdencia...), não é fora de propósito ter de triplicar estes números para poder, assim, estimar a provável incidência de acidentes no país. Isto elevaria à casa dos trés milhões o nimero de acidentes por ano, com as suas óbvias repercussões médicas, sociais e econó- micas, fartamente analisadas em outros estudos.

Se nos detivermos às intoxicações agudas, que são ricamente ilustradas pelas intoxicaçōes por agrotóxicos, o quadro que se apresenta é também considerado de extrema gravidade. Mendes (1986) confirma: os programas de vigilancia epidemiológica de agrotóxicos ou pesticidas, recentemente desenvolvidos em nosso pais, revelam que o problema alcança dimensōes seguramente alarmantes.

Os problemas são graves em diversas áreas: assistência médica; fiscalização; notificação e tratamento dos dados coletados; reconhecimento do nexo entre trabalho e doença; prevenção e cumprimento da legislação, entre outras.

\section{INFORMAÇÃO: A VERDADE OU A FARSA?}

Em relação aos problemas com as informações na área de Saúde do Trabalhador, a literatura apresenta um vasto número de estudos. O mais expressivo exemplo destes problemas está na notificação das doenças profissionais. Mendes (1986) assinala que em relação d̀ ocorréncia das doenças profissionais em nosso pais, ocorre um fenomeno comum a outros paises em mesmo estágio de desenvolvimento, ou seja, sua incidência, a julgar pelas estatisticas oficiais, é extremamente baixa. Prossegue ainda o autor: contudo, nāo é dificil suspeitar que a verdadeira situação não é tão favorável assim. Devem estar ocorrendo tanto a falta de diagnóstico quanto o sub-registro dos casos diagnosticados...

Medrado Faria et al. (1983), a partir de uma investigação realizada no município de Cubatão, São Paulo, revelam a "face oculta" da notificação também nos acidentes de trabalho. Dos 197 episódios de acidentes do trabalho, descritos de modo detalhado pelos trabalhadores entrevistados em seus domicilios, constataram os autores que 35 (17,7\%) referiam ter sido feito o registro no INPS, enquanto que $52(26,3 \%)$ afirmavam não ter sido o acidente registrado. A maioria, ou seja, 89 casos $(45,1 \%)$, mencionou ter sido registrado o acidente apenas no serviço médico da empresa ou em outros serviços médicos. Além disso, 21 
casos $(10,6 \%)$ não sabiam se tinham ou não sido registrados.

Possas (1981), que estudou exaustivamente a questão das informações, sintetiza claramente as razōes da subnotificação: ...os fatores que explicam o sub-registro dos acidentes seriam: a existência de cerca de $40 \%$ de trabalhadores no pais sem carteira assinada; as restrições que a legislação acidentária vem progressivamente sofrendo na conceituação do acidente $e$ das doenças do trabalho; as restriçōes à concessão dos beneficios; as restriçōes no acesso ao Judiciário; e, finalmente, a tendência crescente, favorecida pela Previdência Social, no sentido de se transferir as empresas a responsabilidade pelos acidentes, resolvendo-os no próprio local de trabalho e sem notificá-los ao INPS, o que, além de subestimá-los, ainda desloca o seu registro para os casos mais graves. Conclui-se, portanto, que o problema dos acidentes do trabalho assume, no Brasil, proporções bem mais graves do que as estatisticas existentes permitem sequer vislumbrar.

Poderíamos acrescentar, além destes fatos, os acidentes, principalmente de trajeto, atendidos nos serviços de urgência da rede pública que nāo sāo notificados. Além disto, destacamos os óbitos por acidente de trabalho, que não passam pela rede de serviços, sendo diretamente encaminhados aos Institutos Médico-Legais, onde também não são notificados.

\section{COMPETÊNCIA DAS AÇÕES}

Uma característica marcante na política de Saúde do Trabalhador é a fragmentação das responsabilidades, percebida claramente na existência de inúmeras instituições com atribuições de intervenção na área.

A multiplicidade de ações na área de Saúde do Trabalhador, com reflexos desanimadores no que tange aos resultados, é uma constatação histórica fartamente documentada por vários estudiosos.

A despeito de se atribuir ao Sistema Único de Saúde - SUS - a partir de sua regulamentação pela Lei 8080 , de 19 de setembro de 1990, a responsabilidade pela assistência médica ao doente e ao acidentado do trabalho, pressupondo o atendimento na rede como um todo, esta continua sendo prestada nos moldes do Instituto Nacional de Assistência Médica e Previdência Social - INAMPS -, mantendo o modelo anacrônico de convênios especificos com prestadores de serviços privados.

As ações de reabilitação não foram incorporadas ao SUS, mantendo-se sob a responsabilidade do Ministério do Trabalho e Previdência Social - MTPS -, dentro da estrutura do Instituto Nacional de Seguridade Social - INSS. Este fato contraria frontalmente a mesma lei do SUS no seu artigo $6^{\circ}$, parágrafo $3^{\circ}$, em que o entendimento da Saúde do Trabalhador, para efeito da execução de ações pelo SUS, passa pela reabilitação da saúde dos trabalhadores.

As ações de fiscalização dos ambientes de trabalho continuam sendo executadas pelo MTPS/INSS, pelas Coordenações de Relações do Trabalho, ex-Delegacias Regionais do Trabalho - DRTs. Entendemos que a fiscalização dos ambientes de trabalho é parte essencial na execução das ações de vigilância sanitária. Estas açōes devem ser realizadas numa perspectiva da prevenção, a partir do mapeamento de riscos, mecanismos de vigilância epidemiológica, programas de controle e outras formas de abordagem. Cabe ressaltar que as ações de vigilância sanitária são da alçada do SUS, não seguindo a lógica do modelo tradicional do MTPS, em que o exercício das fiscalizações se dá através de denúncias e demandas pontuais.

Experiências nesse sentido vêm sendo realizadas há cerca de uma década em São Paulo e, mais recentemente, no Rio de Janeiro pelas secretarias estaduais e municipais de saúde. Institucionalizadas como Programa de Saúde do Trabalhador, são o resultado de mecanismos de pressão sobre os órgãos públicos de saúde, por parte de setores combativos do movimento sindical, em articulação com técnicos das secretarias de saúde sensibilizados e comprometidos com as lutas pela transformação das condiçōes de trabalho.

A análise dos mecanismos de notificação, e dos dados deles resultantes, não é voltada para a produção de informações capazes de serem trabalhadas epidemiologicamente. Mais uma vez, contraria-se a lei, mantendo-se na estrutura do INSS o poder de deter informações que, embora pudessem alimentar um sistema riquíssimo de vigilância epidemiológica, têm servido apenas aos objetivos financeiros de atender às 
obrigaçōes pecuniárias decorrentes dos agravos à saúde dos trabalhadores.

A persistência desta lógica parcializada faz com que tanto a política de execução das ações como o próprio indivíduo permaneçam fragmentados. O trabalhador, já comprometido pelo dano à sua saúde imposto pelas condiçōes inadequadas dos processos de produção, é jogado de um lado a outro, numa peregrinação institucional irracional e perversa.

Do ponto de vista dos recursos humanos para a área de Saúde do Trabalhador, o quadro que se apresenta é de uma multiplicidade de órgãos formadores com visōes diferenciadas. De um lado, a formação tradicional visando suprir um mercado de trabalho voltado para os interesses patronais, tendo em vista a necessidade do cumprimento da legislação, que obriga as empresas a constituírem os Serviços Especializados em Engenharia de Segurança e em Medicina do Trabalho - SESMT. Historicamente, a Fundação Jorge Duprat de Figueiredo de Segurança e Medicina do Trabalho - Fundacentro -, tem sido a responsável pela organização e supervisão destes cursos.

Por outro lado, temos a formação promovida pelas universidades, dentro de uma concepção referenciada à saúde pública. Estes recursos humanos são absorvidos, em sua quase totalidade, pelos niveis centrais da administração pública.

Este modo de organização dos aparelhos formadores para a área gera uma carència de profissionais capazes de dar conta das necessidades de atenção aos trabalhadores doentes e acidentados, ao nível dos serviços de atendimento.

Enfim, existe uma organização, na área de Saúde do Trabalhador, que se caracteriza pela lógica da "compartimentalização". As ações são estanques, não-integradas e executadas por órgãos distintos e distanciados institucionalmente.

\section{MARGINALIDADE E FRAGMENTAÇÃO}

Os estudos que tratam da Saúde do Trabalhador, dentre os quais destacamos o de Mendes (1986), propōem a integração das açōes, a partir do estabelecimento de colegiados interinstitucio- nais que dêem conta da formulação da política, do planejamento das ações e da sua execução. Esta experiência, de certo modo inédita, não foi ainda colocada em prática no Brasil, a não ser de forma pontual e isolada, a partir de programas de Saúde do Trabalhador.

A efetivação da proposta de integração é importante como estratégia de mudança na abordagem da questão, servindo para atenuar as dificuldades existentes, mas não para resolvê-las em definitivo. Isto porque a integração institucional, mesmo levada a pleno êxito, não representa o novo para o setor. Utilizando-nos de uma metáfora, poderemos dizer que a proposta de integração é como confeccionar uma roupa nova com velhos retalhos, uma vez que a sua efetivação pura e simples termina por reunir instituições que trazem, na sua prática e no corporativismo de seus quadros, vícios estruturais gravíssimos, resultantes de uma política historicamente ineficiente para a área.

$O$ fato de não haver uma contrapartida a esta situação, no sentido de priorizar ações efetivas capazes de fazer frente à extrema gravidade do problema, nos leva a questionar se esta omissão oficial é intencional, como expressão da pressão da classe patronal dentro do aparelho de Estado, se ocorre por negligência na formulação de uma política eficaz para o setor, ou se ambas.

É pertinente ressaltar o caráter de marginalidade da área de Saúde do Trabalhador, pois mesmo as instituições responsáveis pelas ações apresentam um interesse secundário pela questão. Corrobora este fato a persistente inexistência de estruturas organizacionais próprias para este fim, a nivel das secretarias estaduais e municipais de saúde, com exceções pontuais.

O processo de absorção das ações da Saúde do Trabalhador, por parte do SUS, vem apresentando diversos problemas e, até o momento, não podemos afirmar que as mesmas estejam sendo executadas eficazmente.

Enfatizar, na análise da política de Saúde do Trabalhador, tanto a subnotificação de doenças e acidentes quanto a questão da integração institucional é entender que estes aspectos sinalizam perfeitamente a problemática da área. De um lado, a marginalidade de que se reveste a questão da Saúde do Trabalhador no contexto do setor saúde. De outro, a fragmentação de atribuições e responsabilidades na área. Não 
bastassem estas formas de apresentação do problema, o descaso com que é tratada a Saúde do Trabalhador mostra claramente o descompromisso da classe dirigente brasileira com a "morte lenta" da classe trabalhadora no processo de trabalho.

A discussão que desenvolvemos até o momento permite apontar algumas premissas fundamentais para avançar na análise política atual para a área:

- O modelo atual de atenção à Saúde do Trabalhador, no atendimento a interesses hegemôni$c o s$, encerra uma lógica perversa que vem penalizando os trabalhadores com a perda de sua saúde. É um modelo fracassado, do ponto de vista dos interesses da classe trabalhadora, que, por isso, deve ser substituído por outro que tenha na preservação da saúde dos trabalhadores o seu real objetivo;

- A classe trabalhadora brasileira, por questões conjunturais historicamente determinadas, não tem dado à questão da Saúde do Trabalhador a importância necessária, capaz de dar conta de sua magnitude;

- As tentativas de intervenção na área da Saúde do Trabalhador, buscando superar suas dificuldades, têm levado à criação de novos espaços institucionais, que, de certa forma, contribuem para aumentar a fragmentação já existente;

- A intervenção do aparelho de Estado nos ambientes de trabalho tem servido para a legitimação do risco, na medida em que, por um lado, é estritamente tecnicista, considerando o trabalhador como apêndice da máquina e, por outro, legaliza o risco, através da indenização pelo trabalho insalubre e perigoso.

Todo este quadro caótico de que se reveste a Política Nacional de Saúde do Trabalhador suscita-nos uma série de questōes: Por que a Política Nacional de Saúde do Trabalhador é tratada de forma marginal dentro da Política Nacional de Saúde? Por que esta política continua sendo organizada numa lógica da fragmentação? Até que ponto as tentativas de romper com a fragmentação da área têm obtido resultados satisfatórios? De que forma os trabalhadores percebem a Política de Saúde do Trabalha- dor? Houve uma mudança de conceituação de acidente do trabalho para a Saúde do Trabalhador, a partir do movimento da Reforma Sanitária, que culminou com a criação do SUS? Como os vários atores institucionais trabalharam a questão da Saúde do Trabalhador nos últimos anos e qual a sua relação com o projeto setorial da saúde? Qual foi a contribuição trazida pela $1^{\mathrm{a}}$ Conferência Nacional de Saúde dos Trabalhadores para a área? Em que medida as mudanças recentemente ocorridas na legislação modificaram a realidade da área? As diferentes açōes executadas em diversas regiōes do país têm como base a discussão geral da Reforma Sanitária ou estas diferenças expressam a inexistência de pressupostos gerais para a área? Responder a estas questões é o desafio que se coloca a todos aqueles que pretendem aprofundar sua compreensão na área.

\section{POLÍTICA ACIDENTÁRIA E POLITICA ACIDENTADA}

A possibilidade de transformação da sociedade tem nos setores chamados sociais o seu combustível principal. É nas áreas de habitação, educação, transporte, trabalho e saúde que se vêem desnudadas as injustiças que ferem a dignidade humana, negando os atributos básicos da cidadania.

O discurso neoliberal da modernidade enfatiza as questōes da livre iniciativa, da competição individual, da economia de mercado como panacéia para curar as mazelas do mundo. É ingênuo acreditar nisto, assim como têm sido ingenuamente enganadas as classes oprimidas ao longo da história da humanidade.

A crise sócio-econômica e, principalmente, política em que o país encontra-se mergulhado nestes últimos anos deve funcionar, contraditoriamente, como impulsionadora de conquistas para o campo social. Estabelecer este referencial para a área de Saúde do Trabalhador é poder superar os desafios para reverter o dramático quadro de morbi-mortalidade da classe trabalhadora brasileira.

Portanto, a discussão da Política de Saúde do Trabalhador deve compreender a extensão da Política de Saúde, com todas as suas interfaces, e pormenorizá-la em todos os seus aspectos de 
determinação estrutural e conjuntural. Pressupõe buscar questões no âmago da organização do processo de produção e entendê-lo na realidade nacional em que se expressa, onde o desrespeito ao trabalhador ultrapassa os limites institucionais. Não basta identificar empecilhos e propor superações técnicas. O compromisso de mudança deve conter o paradigma do direito à vida.

A possibilidade de se executar uma política eficiente para a área está relacionada à formação de quadros não só tecnicamente competentes, mas principalmente comprometidos com a questão ideológica que envolve a Saúde do Trabalhador. Some-se a isto a necessidade da responsabilidade por parte dos poderes federal, estaduais e municipais na construção de serviços de saúde eficientes que privilegiem a prevenção em saúde. Ainda há que se destacar o compromisso que a classe empresarial deve assumir pela responsabilidade dos danos que historicamente causam à saúde do trabalhador, a partir da imposição de processos de produção sujos e obsoletos.

Finalmente, ao se pensar a construção da política para a área, o princípio da participação dos trabalhadores deve ser o seu norteador, sem os quais continuaremos a escrever a história das doenças, e nunca a história da saúde, como parte de um processo real de conquista da democracia no Brasil.

\section{AGRADECIMENTOS}

Este texto contou com a relevante contribuição dos mestrandos de Saúde Pública da Ensp/Fiocruz Fátima Sueli Neto Ribeiro e Luiz Sérgio Brandão de Oliveira, em reflexões conjuntas que subsidiaram a elaboração do mesmo.

\section{RESUMO}

OLIVEIRA, M. H. B. de \&

VASCONCELLOS, L. C. F. Política de

Saúde do Trabalhador no Brasil: Muitas

Questōes Sem Resposta. Cad. Saúde Públ., Rio de Janeiro, 8 (2): 150-156, abr/jun, 1992.

Este artigo enfoca a Política Nacional de Saúde do Trabalhador, na perspectiva da expressão do descaso que esta representa frente ao quadro dramático de morbi-mortalidade da classe trabalhadora brasileira.

Indica os principais problemas que a política apresenta, destacando questöes como a subnotificação das doenças profissionais e dos acidentes de trabalho; a competência das ações, denunciando a fragmentação de responsabilidades a partir da existência de diversas instituições e órgãos com atribuições de intervenção na área; a forma marginal, historicamente estabelecida, como é tratada a Política de Saúde do Trabalhador no contexto da Política Nacional de Saúde; as dificuldades na formação de recursos humanos, entre outras.

Aponta para a necessidade de uma política que assegure aos trabalhadores brasileiros a transformação real do grave quadro de mortes e doenças em que encontram-se submetidos, desencadeando processos preventivos de fato, a partir da reestruturação dos processos produtivos e tendo os trabalhadores como condutores desta política.

Finalmente, levanta uma série de questões, ainda sem resposta, que possam servir de matéria para investigaçōes, estudos e pesquisas na área.

Palavras-Chave: Políticas de Saúde; Trabalhador, Saúde

\section{REFERÊNCIAS BIBLIOGRÁFICAS}

ABRASCO (Comissão de Saúde e Trabalho), 1990. Saúde e Trabalho: Desafios para uma Política. 70 p. Rio de Janeiro: Abrasco.

FALEIROS, V. P., 1984. Segurança do Trabalho $x$ Segurança do Capital. Tese de Doutorado, Montreal: Universidade de Montreal. 
MENDES, R., 1986. Doutrina e Prática da Integração da Saúde Ocupacional no Setor Saude: Contribuição para definição de uma Politica. Tese de Livre Docência, São Paulo: Faculdade de Saúde Pública da Universidade de São Paulo. POSSAS, C. A., 1981. Saúde e Trabalho: A Crise da Previdência Social. Rio de Janeiro: Graal.

TAMBELLINE, A. T., 1974. Contribuiçāo à Análise Epidemiológica dos Acidentes de Trânsito. Tese de Doutorado, Campinas: Universidade de Campinas. 